\title{
КОНСТИТУЦИОНАЛЬНЫЕ ОСОБЕННОСТИ ВОЗРАСТНОЙ ДИНАМИКИ ВРЕМЕНИ ПРОСТЫХ СЕНСОМОТОРНЫХ РЕАКЦИЙ ШКОЛЬНИКОВ
}

\author{
(C) Мельник В.А. ${ }^{1}$, Мельник С.Н. ${ }^{1}$, Ткаченко П.В. ${ }^{2}$ \\ ${ }^{1}$ Кафедра нормальной физиологии Гомельского государственного медицинского университета, \\ Гомель, Республика Беларусь; ${ }^{2}$ кафедра нормальной физиологии им. профессора А.В. Завьялова \\ Курского государственного медицинского университета, Курск
}

E-mail: melnik76@tut.by

В статье представлены результаты исследования времени простых сенсомоторных реакций на световой и звуковой раздражители городских школьников (1693 мальчика и 1757 девочек) общеобразовательных школ в возрасте от 7 до 17 лет различных типов телосложения. В результате проведенных исследований установлено, что время ответной реакции на световой и звуковой раздражители зависит от типа телосложения обследуемого. Мальчики всех возрастных групп и соматотипов обладают более высокой скоростью ответной реакции на действие световых и звуковых раздражителей по сравнению с девочками. Физиологическое укорочение ответной реакции на раздражители отмечалось в более раннем возрасте у мальчиков и девочек гиперсомных соматотипов. Обследованные двух половых групп с мезои лептосомными соматотипами с возрастом становятся более реактивными на действие раздражителей по сравнению с гиперсомными.

Ключевые слова: сенсомоторные реакции, соматотип, школьники, возрастная динамика.

\section{CONSTITUTIONAL FEATURES OF AGE-RELATED DYNAMICS OF TIME OF SIMPLE SENSOMOTOR REACTIONS OF SCHOOL CHILDREN Melnik V.A. ${ }^{l}$, Melnik S.N. ${ }^{l}$, Tkachenko P.V. ${ }^{2}$}

${ }^{1}$ Department of Normal Physiology of Gomel State Medical University, Gomel, Republic of Belarus;

${ }^{2}$ Department of Normal Physiology named after Professor A.V. Zavyalov of Kursk State Medical University, Kursk

The article presents the results of studying the time of simple sensomotor reactions to light and sound irritants of urban secondary school students (1,693 boys and 1,757 girls) aged 7-17 with different body types. As a result of the conducted study it has been found that the time of responses to light and sound irritants depended on the children's body types. The boys of all age groups and somatotypes possess higher rate of the response to the effect of light and sound irritants in comparison with the girls. The physiological shortening of responses to the irritants was noted in the boys and girls with hypersomnic somatotypes at an earlier age. However, the examined children of both groups with mezo- and leptosomnic somatotypes become more responsive to the effect of the irritants over time in comparison with hypersomnic ones.

Keywords: sensomotor reactions, somatotype, school children, age-related dynamics.

Состояние здоровья школьников, как и населения в целом, - не только важный индикатор общественного развития, отражение социальноэкономического и гигиенического благополучия страны, но и мощный экономический, трудовой, оборонный и культурный потенциал общества, фактор и компонент его благосостояния [4].

Оценка функциональных показателей развития ребенка является важным критерием состояния его здоровья. Отклонение этих показателей от нормы часто является первым важным признаком как нарушения функционального состояния организма ребенка, так и уже имеющегося у него заболевания. Показатели физического развития отражают процесс формирования организма на отдельных этапах постнатального онтогенеза (индивидуального развития), когда генотипический потенциал наиболее интенсивно преобразуется в фенотипические проявления. Поэтому детский организм, в отличие от организма взрослого, в большей степени реагирует на воздействие био- логических и социальных факторов внешней среды $[2,3,13]$.

Данные о функционировании органов и систем используют в качестве критериев оценки физического развития. Эти показатели обнаруживают выраженные связи с морфологическим статусом $[7,14]$. Одним из важных показателей, характеризующим состояние нервной системы ребенка, является время ответной реакции на простые сенсорные раздражители (световые и звуковые).

Время простой сенсомоторной реакции есть основной показатель базовых (природных) скоростных возможностей человека. Скоростные возможности человека (отраженные в этом показателе), особенно в их моторной части, являются в большей степени природными и мало изменяемыми под воздействием тренировки. Измерение параметров времени простой сенсомоторной реакции позволяет определить быстроту и стабильность сенсомоторного реагирования $[1,5,9,10]$. 
Несмотря на то, что показатели сенсомоторных реакций являются достаточно важным показателем, характеризующим развитие ребенка, научных работ, посвященных их изучению, имеется не так много $[8,13]$.

Цель исследования - изучить половозрастную динамику показателей сенсомоторной реактивности на световой и звуковой раздражители у городских школьников различных типов телосложения в возрасте от 7 до 17 лет.

\section{МАТЕРИАЛЫ И МЕТОДЫ ИССЛЕДОВАНИЯ}

Объектом исследования явились учащиеся общеобразовательных школ г. Гомеля в возрасте от 7 до 17 лет. На протяжении двух учебных лет (2010-2012 гг.) было проведено комплексное морфофункциональное обследование 1693 мальчиков и 1757 девочек - всего 3450 школьников, не имеющих существенных отклонений в состоянии здоровья (I и II группы здоровья). Все исследования проводились с письменного согласия родителей, разрешения Управления здравоохранения Гомельского областного исполнительного комитета, а также на основании заключенных договоров о сотрудничестве между УО «Гомельский государственный медицинский университет» и средними образовательными школами г. Гомеля.

Для определения времени латентного периода простых сенсомоторных реакций у детей и подростков на световой и звуковой раздражитель использовался экспресс-диагностический прибор «Барьер» (ROK 1, Россия).

Исследования проводились в положении испытуемого сидя на стуле, в спокойном состоянии. Вначале определялось время латентного периода сенсомоторной реакции (ЛПСМР) обследуемого на световой раздражитель, затем - на звуковой. Прибор учитывал и запоминал время от начала действия светового или звукового сигнала до нажатия кнопки управления. Последнее нажатие кнопки управления сопровождалось высвечиванием на индикаторе усредненного времени реакции из 20 ответов на свет и звук в миллисекундах [15]. Показатели ЛПСМР на световой и звуковой раздражители измерялись три раза. В карте обследования фиксировался средний показатель.

Изменчивость динамики физиологического снижения ЛПСМР показателей в интервале 7-17 лет прослежена путем анализа их абсолютных и относительных ежегодных прибавок. Относительные прибавки рассчитаны в процентах от общего прироста за весь изучаемый возрастной период.

Определение соматотипической принадлежности осуществлялось по новой количественной схеме «Способ количественной оценки типов телосложения по комплексу антропометрических показателей», разработанной и внедренной в практическую деятельность группой белорусских ученых И.И. Саливон, Н.И Полиной и В.А. Мельником [11]. Методика предусматривает выделение трех основных вариантов телосложения (соматотипов): астенизированного лептосомного, мезосомного и адипозного гиперсомного, а также четырех переходных - лептосомного, мезолептосомного, мезогиперсомного и гиперсомного [12].

В исследовании после определения типа телосложения обследуемые в пределах одной возрастной выборки были распределены по подгруппам в зависимости от конституциональных особенностей телосложения. В связи с тем, что астенизированные лептосомные, лептосомные, гиперсомные и адипозногиперсомные дети и подростки встречались редко, после проведения соматотипирования они были объединены в три основные группы: лептосомные, состоящие из астенизированных лептосомных и лептосомных; мезосомные; гиперсомные, включившие адипозных гиперсомных и гиперсомных обследованных. Изучение динамики времени латентного периода простых сенсомоторных реакций у детей и подростков на световой и звуковой раздражитель осуществлено с учетом соматотипа [12].

Статистическая обработка осуществлялась с использованием пакета прикладных статических программ «STATISTICA7.0». Полученные peзультаты представлены в виде средних арифметических величин (M) и стандартного отклонения (SD). Значимость различий оценивалась по критерию Манна-Уитни (U-критерий). Результаты анализа считались статистически значимыми при $\mathrm{p}<0,05$ [6].

\section{РЕЗУЛЬТАТЫ ИССЛЕДОВАНИЯ И ИХ ОБСУЖДЕНИЕ}

В результате анализа полученных данных установлено, что у обследованных двух половых групп всех соматотипов время ЛПСМР на световой и звуковой раздражители с возрастом статистически значимо $(\mathrm{p}<0,001)$ снижается (таблицы 1,2$)$. Так, среди мальчиков лептосомных соматотипов ЛПСМР на световой раздражитель сни-

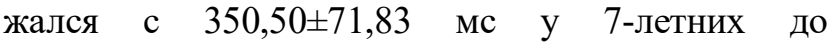

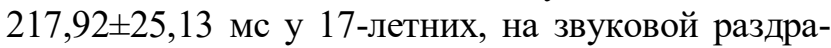
житель - от $313,15 \pm 36,15$ до $175,00 \pm 17,30$ мс соответственно. Уменьшение ЛПСМР на световой раздражитель у мальчиков мезосомного соматотипа в возрастном интервале от 7 до 17 лет составило 130,93 мс, на звуковой - на 129,46 мс, у гиперсомных - на 96,44 мс и на 134,54 мс соответственно. 
Статистически значимое ( $<<0,001)$ физиологическое снижение ЛПСМР на световой раздражитель у девочек лептосомного типа телосложения происходило от $365,83 \pm 48,00$ мс у 7-летних до $210,67 \pm 11,13$ мс у 17-летних, на звуковой от $334,29 \pm 83,80$ до $181,25 \pm 19,99$ мс соответственно. ЛПСМР на световой раздражитель у девочек мезосомного соматотипа в возрастном интервале от 7 до 17 лет уменьшался на 167,15 мс, на звуковой на 188,31 мс, у гиперсомных на $155,16,44$ мс и на 150,50 мс соответственно (таблицы 1,2 ).

В возрастном диапазоне от 7 до 17 лет время ЛПСМР на световой и звуковой раздражители ниже у мальчиков всех типов телосложения по сравнению с девочками-сверстницами. Значимые половые различия показателей ЛПСМР на световой раздражитель чаще выявлялись между гиперсомными, а на звуковой - между лептосомными сверстниками $(\mathrm{p}<0,05-0,001)$.

За весь изучаемый возрастной период наименьшее снижение времени ЛПСМР на свето- вой раздражитель происходило у мальчиков и девочек гиперсомных соматотипов, а наибольшее - у девочек мезосомных и мальчиков лептосомных типов телосложения на звуковой раздражитель (таблицы 1, 2).

Таким образом, у представителей мезо- и лептосомных типов телосложения с возрастом сокращается ЛПСМР на действие раздражителей по сравнению с гиперсомными, что свидетельствует о сокращение у них времени ответных реакций на действие стимулов.

Периоды наиболее существенного физиологического уменьшения времени ЛПСМР на световой и звуковой раздражители раньше всего зафиксированы у мальчиков гиперсомных соматотипов с 9 до 11 лет, а у мезо- и лептосомных - с 10 до 11 лет (рис. 1а, 2a).

Среди девочек всех типов телосложения наиболее активное снижение времени ЛПСМР на световой раздражитель отмечено с 8 до 9 лет (рис. 1б).

Таблица 1

Половозрастная динамика времени сенсомоторной реактивности на световой раздражитель (мс) школьников в зависимости от соматотипа

\begin{tabular}{|c|c|c|c|c|c|c|}
\hline \multirow{3}{*}{ Возраст, лет } & \multicolumn{6}{|c|}{ Тип телосложения } \\
\hline & \multicolumn{2}{|c|}{ лептосомный } & \multicolumn{2}{|c|}{ мезосомный } & \multicolumn{2}{|c|}{ гиперсомный } \\
\hline & $\mathrm{M}$ & SD & M & SD & M & SD \\
\hline \multicolumn{7}{|c|}{ Мальчики } \\
\hline 7 & 350,50 & 71,81 & 343,67 & 67,37 & 319,87 & 47,61 \\
\hline 8 & 330,00 & 54,96 & 315,35 & 60,73 & 317,70 & 33,89 \\
\hline 9 & 310,50 & 53,60 & 297,06 & 56,06 & 298,55 & 53,62 \\
\hline 10 & 288,31 & 42,72 & 279,55 & 45,44 & 269,56 & 17,56 \\
\hline 11 & 239,50 & 13,78 & 251,91 & 26,94 & 251,26 & 31,12 \\
\hline 12 & 238,41 & 26,69 & 251,84 & 29,18 & 250,21 & 40,88 \\
\hline 13 & 237,77 & 14,21 & 240,05 & 30,19 & 246,24 & 47,50 \\
\hline 14 & 236,88 & 36,96 & 230,57 & 17,46 & 233,70 & 32,85 \\
\hline 15 & 228,22 & 31,68 & 226,24 & 21,77 & 230,07 & 44,77 \\
\hline 16 & 224,88 & 20,02 & 221,13 & 18,29 & 226,65 & 35,67 \\
\hline 17 & 217,92 & 25,13 & 212,74 & 20,41 & 222,43 & 17,09 \\
\hline \multicolumn{7}{|c|}{ Девочки } \\
\hline 7 & 391,04 & 94,17 & 388,89 & 83,37 & 365,83 & 48,00 \\
\hline 8 & 375,39 & 109,45 & 347,54 & 53,38 & 365,30 & 98,14 \\
\hline 9 & 313,40 & 33,39 & 293,57 & 27,04 & 306,54 & 32,21 \\
\hline 10 & 297,04 & 65,80 & 281,84 & 31,40 & 281,83 & 47,27 \\
\hline 11 & 283,17 & 70,47 & 252,93 & 31,14 & 281,55 & 35,82 \\
\hline 12 & 253,19 & 25,38 & 251,92 & 38,81 & 255,73 & 37,20 \\
\hline 13 & 240,43 & 37,89 & 245,89 & 43,45 & 249,32 & 41,02 \\
\hline 14 & 237,92 & 29,61 & 234,60 & 29,92 & 235,16 & 36,64 \\
\hline 15 & 236,31 & 49,70 & 230,05 & 20,55 & 227,10 & 26,79 \\
\hline 16 & 231,44 & 30,77 & 225,85 & 27,52 & 224,50 & 25,75 \\
\hline 17 & 230,00 & 18,81 & 221,74 & 36,14 & 210,67 & 11,13 \\
\hline
\end{tabular}


Таблица 2

Половозрастная динамика времени сенсомоторной реактивности на звуковой раздражитель (мс) школьников в зависимости от соматотипа

\begin{tabular}{|c|c|c|c|c|c|c|}
\hline \multirow{3}{*}{ Возраст, лет } & \multicolumn{6}{|c|}{ Тип телосложения } \\
\hline & \multicolumn{2}{|c|}{ лептосомный } & \multicolumn{2}{|c|}{ мезосомный } & \multicolumn{2}{|c|}{ гиперсомный } \\
\hline & $\mathrm{M}$ & $\mathrm{SD}$ & $\mathrm{M}$ & $\mathrm{SD}$ & $\mathrm{M}$ & SD \\
\hline \multicolumn{7}{|c|}{ Мальчики } \\
\hline 7 & 313,15 & 36,35 & 302,43 & 53,27 & 305,83 & 46,36 \\
\hline 8 & 301,15 & 65,11 & 293,50 & 69,88 & 279,93 & 52,61 \\
\hline 9 & 266,94 & 64,71 & 278,69 & 36,77 & 271,11 & 55,07 \\
\hline 10 & 256,31 & 54,32 & 254,52 & 53,00 & 237,03 & 24,02 \\
\hline 11 & 202,00 & 28,72 & 217,50 & 31,02 & 212,94 & 22,83 \\
\hline 12 & 195,55 & 16,33 & 212,37 & 35,60 & 208,83 & 36,00 \\
\hline 13 & 187,79 & 20,62 & 207,38 & 30,39 & 205,67 & 33,45 \\
\hline 14 & 180,00 & 13,69 & 193,31 & 23,85 & 202,32 & 37,52 \\
\hline 15 & 178,89 & 15,37 & 190,90 & 20,52 & 195,24 & 40,56 \\
\hline 16 & 176,25 & 18,45 & 187,85 & 17,61 & 181,38 & 18,45 \\
\hline 17 & 175,00 & 17,30 & 172,97 & 19,34 & 171,29 & 26,43 \\
\hline \multicolumn{7}{|c|}{ Девочки } \\
\hline 7 & 334,29 & 83,80 & 368,00 & 111,25 & 321,30 & 47,31 \\
\hline 8 & 304,89 & 61,06 & 319,26 & 113,08 & 295,70 & 78,48 \\
\hline 9 & 271,95 & 76,18 & 287,07 & 54,64 & 292,19 & 50,77 \\
\hline 10 & 266,50 & 55,03 & 251,06 & 39,20 & 237,17 & 43,46 \\
\hline 11 & 230,42 & 30,53 & 231,52 & 61,18 & 231,65 & 33,26 \\
\hline 12 & 228,50 & 48,25 & 213,20 & 36,26 & 210,71 & 28,65 \\
\hline 13 & 196,46 & 33,83 & 209,19 & 50,71 & 209,03 & 38,34 \\
\hline 14 & 195,50 & 17,81 & 200,67 & 27,14 & 195,68 & 37,55 \\
\hline 15 & 193,73 & 19,38 & 191,73 & 26,83 & 190,81 & 25,83 \\
\hline 16 & 187,77 & 27,54 & 188,83 & 22,31 & 188,40 & 21,86 \\
\hline 17 & 181,25 & 19,99 & 179,69 & 35,72 & 170,80 & 13,14 \\
\hline
\end{tabular}

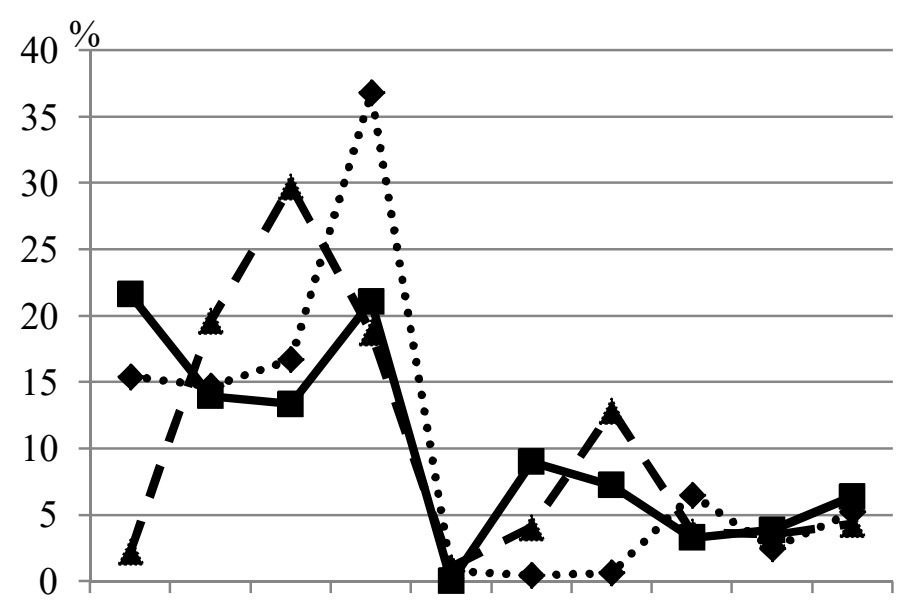

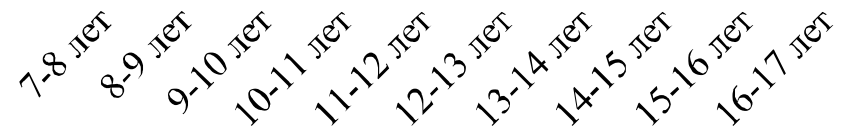

Возрастной период

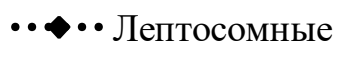

$\rightarrow$ Мезосомные

-А-Гиперсомные

A.
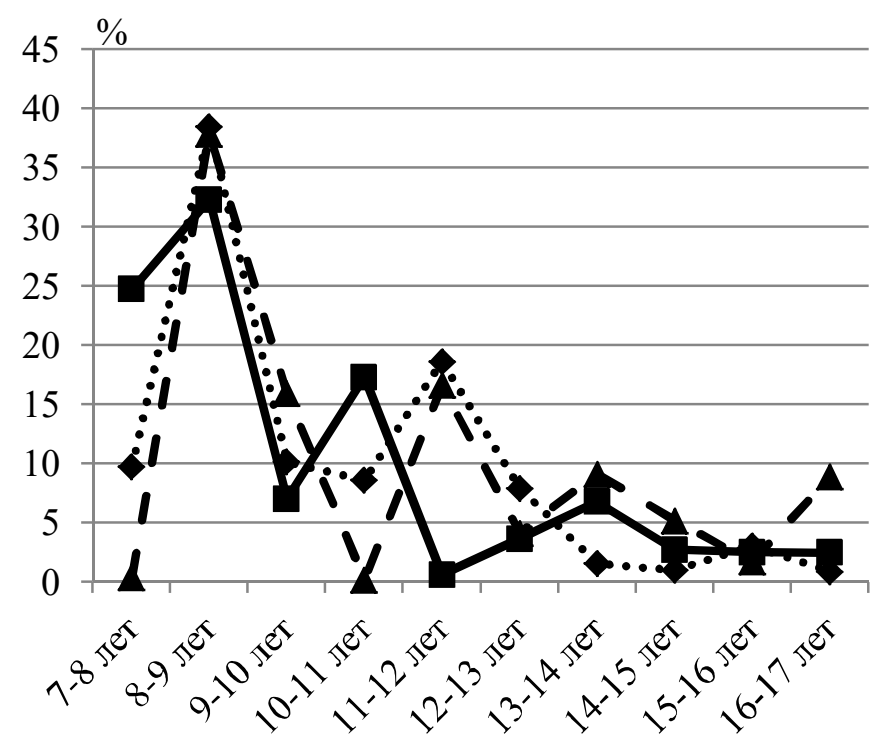

Возрастной период

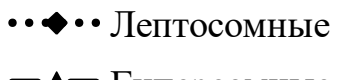

-2 Meзосомные

- $\boldsymbol{-}$ - Гиперсомные

Б.

Рис. 1. Относительное снижение времени ЛПСМР на световой раздражитель у мальчиков (а) и девочек (б) различных соматотипов. 


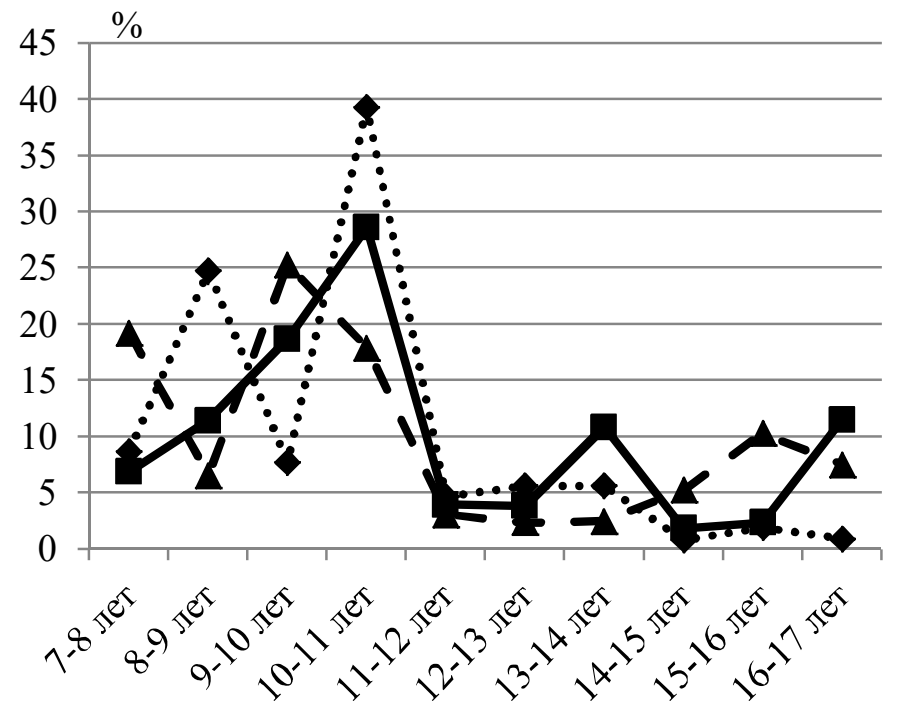

Возрастной период

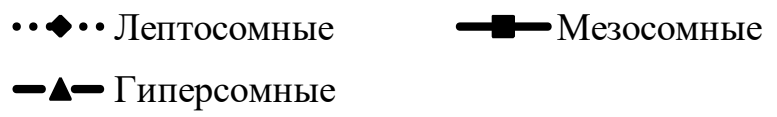

A.

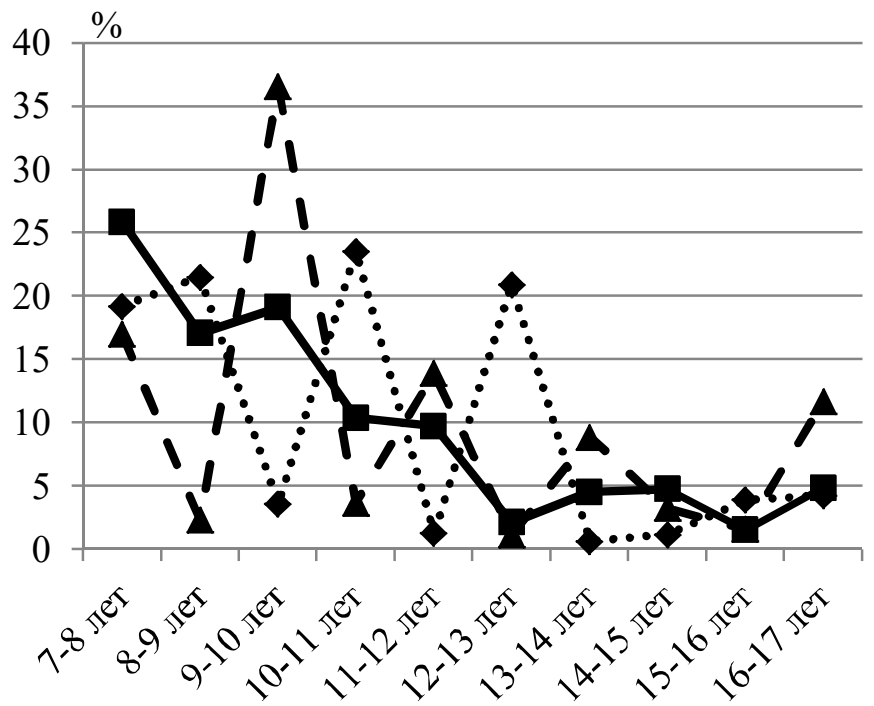

Возрастной период

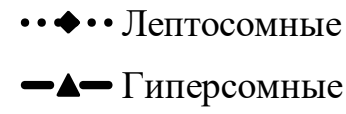

- Мезосомные

Б.

Рис. 2. Относительное снижение времени ЛПСМР на звуковой раздражитель у мальчиков (а) и девочек (б) различных соматотипов.

На звуковой раздражитель у девочек мезосомных соматотипов отмечено постепенное снижение показателя на протяжении всего изучаемого возрастного периода (рис. 2б). У представительниц гиперсомных соматотипов с 9 до 10 лет выявлено максимальное снижение ЛПСМР на звуковой раздражитель, а у девочек лептосомных типов телосложения отмечено два возрастных интервала наибольшего снижения времени ответных реакций: 10-11 лет и 12-13 лет.

Время ЛПСМР на световой и звуковой раздражители у обследованных всех соматотипов имело статистически значимую отрицательную взаимосвязь практически со всеми соматометрическими показателями (кроме толщины кожножировых складок), что свидетельствует об увеличении реактивности организма на действие раздражителей с ростом антропометрических показателей. При этом более высоких значений коэффициенты корреляции достигали между изучаемыми показателями у лепто- и мезосомных исследованных двух половых групп, однако у мальчиков они были выше по сравнению с девочками.

Таким образом, анализ соматотипических особенностей возрастной динамики время ЛПСМР на световой и звуковой раздражители показал, что интенсивность физиологического снижения показателей зависит от типа телосложения ( $<<0,05-0,001)$.

В возрастном диапазоне от 7 до 17 лет время ЛПСМР на световой и звуковой раздражители ниже у мальчиков всех типов телосложения по сравнению с девочками-сверстницами, что свидетельствует о более высокой скорости ответных реакций мальчиков на действие внешних раздражителей.

Максимальное физиологическое снижение времени латентного периода сенсомоторной реактивности (физиологическое ускорение ответной реакции) на световой раздражитель происходит у девочек всех соматотипов с 8 до 9 лет. Среди мальчиков гиперсомного типа телосложения наибольшее снижение показателя на световой стимул начиналось раньше (9-11 лет) по сравнению с ровесниками других соматотипов на 1 год (10-11 лет). Значительное физиологическое укорочение ответной реакции на звуковой раздражитель также отмечено в более раннем возрасте (на 1 год) у мальчиков (с 9 до 11 лет) и девочек (с 9 до 10 лет) гиперсомных соматотипов по сравнению со школьниками других типов телосложения.

За весь изучаемый возрастной период минимальное снижение времени ЛПСМР происходило у мальчиков и девочек гиперсомных типов телосложения на световой раздражитель, а наибольшее - у девочек мезосомных соматотипов и мальчиков лептосомных типов на звуковой раздражитель. Таким образом, с возрастом у обследованных с мезо- и лептосомными соматотипами сокращается ЛПСМР на действие раздражителей по сравнению с гиперсомными. 


\section{ЛИТЕРАТУРА}

1. Айдаркин Е.К., Павловская М.А. Влияние интенсивности звукового стимула и межстимульного интервала на параметры слухового ССП в условиях реализации простой сенсомоторной реакции // Валеология. - 2013. - № 3. - С. 166-180.

2. Антонова А.А., Ченщова С.Н., Сердюков В.Г. Сравнительная характеристика физического развития детей // Астраханский медицинский журнал. 2012. - T. 7, № 4. - С. 26-29.

3. Антонов О.В., Богачева Е.В., Антонова И.В., Вельматова А.А., Кузьмина А.Л., Филиппов Г.П., Мурашев Е.В. Оценка и анализ физического развития детей и подростков // Сибирский медицинский журнал. - 2012. - Т. 27, № 4. - С. 20-24.

4. Безруких М.М. Здоровье школьников, проблемы, пути решения // Сибирский педагогический журнал. - 2012. - № 9. - С. 11-16.

5. Ваганов П.Д. Физическое и нервно-психическое развитие детей первого года жизни // Российский медицинский журнал. - 2011. - № 3. - С. 26-31.

6. Глани С. Медико-биологическая статистика / пер. с англ. Ю.А. Данилова. - М. : Практика, 1999. $459 \mathrm{c}$.

7. Дорохов Р.Н., Чернова В.Н. Интеграция соматометрических и функциональных показателей детей и подростков // Известия Смоленского государственного университета. - 2016. - № 1 (33). - С. 291-297.

8. Камаев О.И., Проскуров Е.М. Особенности развития скоростно-силовых способностей с различными антропометрическими показателями у мальчиков 10-11 лет // Физическое воспитание студентов. - 2012. - № 4. - С. 68-72.
9. Кириллова, Е.А. Физическое и психомоторное развитие детей с задержкой внутриутробного роста: обзор // Акушерство и гинекология. - 2015. № 11. - С. 23-27.

10. Лазаревич К.Л. Физическое и психомоторное развитие детей раннего возраста, больных туберкулезом // Педиатрия - 2010. - Т. 1, № 1. - С. 47-48.

11. Мельник В.А., Саливон И.И. Методика определения типов телосложения детского населения по комплексу антропометрических показателей: учеб.метод. пособие. - Гомель: Изд-во ГомГМУ, 2013. $36 \mathrm{c}$.

12. Мельник В. А. Конституциональные особенности формирования морфофункциональных показателей физического развития и полового созревания городских школьников: монография. - Гомель: Изд-во ГомГМУ, 2015. - 224 с.

13. Полина Н.И. Типологическая изменчивость функциональных признаков у школьников-белорусов и потомков от межнациональных браков // Вестник антропологии: науч. альм. - 2006. - Вып. 14. C. $222-230$.

14. Пономарева O.B. Корреляционная зависимость между антропометрическими и физиометрическими показателями детей // Российский вестник перинатологии и педиатрии. -2015 . - Т. 60, № 4. C. 162.

15. Питкевич Э.С., Штаненко Н.И., Мельник С.Н., Мельник В.A., Заика Э.М. Руководство к практическим занятиям по нормальной физиологии: учеб.метод. пособие; под ред. проф. Э.С. Питкевича. - 2-е изд., стер. - Гомель : УО «ГомГМУ», 2008. - 128 с. 